\title{
Frédéric Dubrana, Dominique Le Ne, François-Xavier Gunepin, Christian Lefèvre: Manuel des voies d'abord en chirurgie orthopédique et traumatologique 2è édition (French)
}

Elsevier Masson, 2014, 157 pp, num. illustr., Softcover, 73,00 € - eBook 49,98 €, ISBN: 978-2-294-70510-6

\section{Pierre Kehr ${ }^{1}$}

Received: 24 July 2015/ Accepted: 25 July 2015/Published online: 21 August 2015

(C) Springer-Verlag France 2015

This beautiful book published within the series of the Books of Group GECO wants to be a guide for a great number of the frequent approaches in orthopedic surgery. It is divided into four parts: upper limb, lower extremity, pelvis and spine and accesses of arthroscopy. Each access is exposed in an identical way: technique-risks-indications. It is magnificently illustrated by drawings color, very realistic.

The work is supplemented by an index allowing a rapid access with the various anatomical entries. Intended as well for the initial surgeons who want to understand and improve their gesture, it is also with advising with the seniors, because it is always useful to be compared. It should be in all the libraries of private clinics and orthopedic hospitals.

Compliance with ethical standards

Conflict of interest None.

Pierre Kehr

pierre.kehr@gmail.com

1 Strasbourg, France 